\title{
Uptake of Cervical Cancer Screening among Women Attending Health Facilities in the City of Bulawayo, 2012
}

\author{
Munekayi Padingani' ${ }^{1}$, Gladys Marape ${ }^{2}$, Zanele Hwalima ${ }^{2}$, Notion Gombe ${ }^{1}$, Ms T. Juru ${ }^{*}$, \\ Mufuta Tshimanga ${ }^{1}$
}

\author{
${ }^{1}$ Department of Community Medicine, University of Zimbabwe, Harare, Zimbabwe \\ ${ }^{2}$ City Health Department, Bulawayo City Council, Bulawayo, Zimbabwe \\ Email: ^tsitsijuru@gmail.com,drmunepadi@gmail.com, gmarape@yahoo.com, zanelehwalima@gmail.com, \\ gombent@gmail.com, mufutatshimanga@gmail.com
}

How to cite this paper: Padingani, M., Marape, G., Hwalima, Z., Gombe, N., Juru, M.T. and Tshimanga, M. (2018) Uptake of Cervical Cancer Screening among Women Attending Health Facilities in the City of Bulawayo, 2012. Open Journal of Epidemiology, 8, 153-163.

https://doi.org/10.4236/ojepi.2018.83013

Received: May 2, 2018

Accepted: August 20, 2018

Published: August 23, 2018

Copyright $\odot 2018$ by authors and Scientific Research Publishing Inc. This work is licensed under the Creative Commons Attribution International License (CC BY 4.0).

http://creativecommons.org/licenses/by/4.0/

\begin{abstract}
Introduction: In Zimbabwe, where cervical cancer is the leading female malignancy, no systematic cervical screening program has been introduced. However, selective or opportunistic screening has been performed since the late 1980s. The Ministry of Health and Child Care is relying on screening, which allows early detection of pre-cancerous cells and diagnosis at early stages but many women are not going for the test and no studies have been done to find out why. This study investigated the women's perception about cervical cancer and its screening using health belief model (HBM) in Bulawayo, where they are two new screening clinics. Methods: We conducted an analytic cross-sectional study. Women from 18 years and above attending health facilities were included in the study. Interviewer administrated questionnaire was used to determine the proportion of screened women and elicit their perception about cervical cancer and its screening. Epi-info version 3.3.2 was used to do bivariate and multivariate analysis. Results: Two hundred women were recruited into the study. The proportion of women who had cervical cancer screening was 52 (26\%). Pap smear only had 35 (17.5\%) had VIAC only, 13 (6.5\%) and Pap smear and VIAC had 4 (2\%). Knowledge of cervical cancer and its screening was poor among participants. In multivariate analysis, awareness of cervical cancer screening [adjusted OR 42.05 (95\% CI 5.63 - 314.04)] was associated with the uptake of cervical cancer screening and perceiving that having multiple sexual partners[adjusted OR 0.33 (95\% CI $0.12-0.88$ )] was independently associated to the uptake of cervical cancer screening. Conclusion: This study demonstrated that lack of awareness of cervical cancer screening is a barrier to the uptake of the screening. Perceiving
\end{abstract}


multiple sexual partners was associated to the uptake of cervical cancer screening. It is therefore necessary to increase awareness in Bulawayo City and educate the community about other risk factors.

\section{Keywords}

Cervical Cancer, Screening, VIAC, Pap Smear, Bulawayo City

\section{Introduction}

Worldwide, cervical cancer is the second most common type of cancer among women [1]. Cervical cancer begins with abnormal changes in the cervical tissue. The risk of developing these abnormal changes is associated with infection with human papillomavirus (HPV) [2]. In addition, early sexual contact, multiple sexual partners, high parity and taking oral contraceptives (birth control pills) increase the risk of cervical cancer, because they increase exposure to HPV. Cigarette smoking increases the growth rate of HPV, HIV infection increases risk because of low immunity [3] [4].

Most of the time, early cervical cancer has no symptoms. Symptoms that may occur can include: abnormal vaginal bleeding between periods, after intercourse, or after menopause, continuous vaginal discharge, which may be pale, watery, pink, brown, bloody, or foul-smelling and periods become heavier and last longer than usual [4].

To prevent cervical cancer and its adverse outcomes, the Centers of Disease Control and Prevention (CDC) recommends a vaccine for Human papillomavirus and a cervical cancer screening [5].

The aim of cervical cancer screening is to detect precancerous lesions and treat them before they progress to invasive cancer. Cytology screening has been shown to be effective in reducing the incidence and mortality from cervical cancer in the developed countries [6] [7] [8] [9].

In most developing countries, women are advised to have their first smear test soon after becoming sexually active and subsequently once every $1-5$ years. Cervical cancer screening methods known are Papanicolaou (Pap) smear, HPV DNA test, Cervicography, Visual inspection with acetic acid (VIA) and visual inspection with Lugol's iodine called VILI [10].

In Zimbabwe, cervical cancer is ranked as the first most frequent cancer among women, and the second most frequent cancer among women between 15 and 44 years of age [11]. According to Zimbabwe National Cancer Registry cervical cancer is the leading cancer in Zimbabwe [12].

Cervical cancer is the leading cause of cancer death for women in Zimbabwe [10]. The Ministry of Health and Child Care is relying on screening, which allows early detection of pre-cancerous cells and diagnosis at early stages but many women are not going for the test as they can hardly afford it. The screening 
options available in Zimbabwe are the pap smear, VIA (Visual Inspection with Acetic Acid). The only currently available, affordable and sustainable large scale screening method is one that is VIA based.

One third (33\%) of the population of the city of Bulawayo are women of childbearing age. A new cervical cancer screening programme other than Pap smear called VIAC (Visual Inspection with Acetic Acid and Cervicography) is in place in Bulawayo since September 2010 and it is only performed at Central Hospitals (Mpilo and United Bulawayo Hospitals). In 2011, 24,055 deliveries were reported in Bulawayo against 5969 cervical cancer screenings. It is recommended that every woman should have a cervical cancer screening 6 weeks after delivery and any sexually active woman 18 years and above should be screened. There is an apparent gap between number of deliveries and number of cervical cancer screening procedures done.

This study determined the factors associated with uptake of cervical cancer screening among women attending health facilities in the City of Bulawayo, the socio-demographic and socio-economic characteristics associated with uptake of cervical cancer screening and the proportion of women attending health facilities who have had cervical cancer screening. Assessed participants' knowledge of cervical cancer including screening, described the women's perceived susceptibility to cervical cancer and the women's perceived benefits of doing cervical cancer screening. This study identified also the women's perceived barriers to seeking cervical cancer screening using Health Belief Model (HBM). The HBM is a psychological health behaviour change model developed to explain and predict health-related behaviours, particularly in regard to the uptake of health services [13].

\section{Methods}

We conducted an analytic cross-sectional study s in Bulawayo City at Mpilo Central hospital, United Bulawayo Hospital, 19 City clinics and Galen house. (Antenatal Clinics, Post Natal Clinics, Casualties, VIAC clinics, Out Patient Department, Gynecologic ward). Only women of 18 years and above, attending those health facilities were included in the study.

An interviewer-administered questionnaire was used to collect data from women on socio-demographic and socio-economic characteristics, previous history of cervical cancer screening, on knowledge of cervical cancer and screening and on women's perception about cervical cancer using health belief model (HBM). Key informants (Head of obstetric and gynecologic department of Mpilo and United Bulawayo Hospitals, sisters working at VIAC clinics, sisters in charge of city clinics and Galen house) were interviewed to know about their knowledge on cervical cancer and its screening methods, qualification of staff, services offered by health facilities.

Permission to carry out the study was sought and obtained from the Health Studies Office, Joint Parirenyatwa Hospital and college of Health Sciences 
Research Committee (JREC), Bulawayo City Council Health Department, Clinical Directors of Central Hospitals and partners of Galen house.

Informed written consent was obtained from study participants. Confidentiality was assured and maintained throughout the study and no names were used in the questionnaire.

EPI-INFO version 3.3.2 was used to generate frequencies, proportions, and medians, measure of associations odd ratio and $95 \%$ confidence intervals. Stratified analysis was performed to assess for possible confounding. Logistic regression analysis was done to determine independent factors of Uptake of cervical cancer screening (Figure 1).

\section{Results}

A total of 200 women were recruited into the study, 19 (9.5\%) from rural areas and $181(90.5 \%)$ from urban areas. Of these, 52 (26\%) had cervical cancer screening and 148 (74\%) did not go for screening. Among women who had cervical cancer screening; 35 (17.5\%) had VIAC only, 13 (6.5\%) had Pap smear only and $4(2 \%)$ had both Pap smear and VIAC (Table 1).

Table 1. Socio-demographic characteristics of participants in Bulawayo city, 2012.

\begin{tabular}{|c|c|c|c|c|c|}
\hline \multirow[t]{2}{*}{ Variable } & \multicolumn{2}{|c|}{$\begin{array}{l}\text { Women who had } \\
\text { cervical cancer } \\
\text { screening }\end{array}$} & \multicolumn{2}{|c|}{$\begin{array}{l}\text { Women who did not } \\
\text { have cervical cancer } \\
\text { screening }\end{array}$} & \multirow[t]{2}{*}{$\mathrm{p}$-value } \\
\hline & $\mathrm{N}=52$ & $(\%)$ & $N=148$ & $(\%)$ & \\
\hline \multicolumn{6}{|l|}{ Religion } \\
\hline -None & 1 & $(1.9)$ & 5 & $(3.4)$ & \multirow{7}{*}{0.2} \\
\hline -Apostolic Sect & 5 & $(9.6)$ & 33 & $(22.3)$ & \\
\hline -Pentecostal & 17 & $(32.7)$ & 50 & $(33.8)$ & \\
\hline -Protestant & 1 & $(1.9)$ & 0 & $(0.0)$ & \\
\hline -Roman Catholic & 6 & $(11.5)$ & 10 & $(6.8)$ & \\
\hline -Traditional & 1 & $(1.9)$ & 2 & $(1.4)$ & \\
\hline -Other Christian & 21 & $(40.4)$ & 48 & $(32.4)$ & \\
\hline \multicolumn{6}{|l|}{ Residence } \\
\hline -Rural & 8 & $(15.4)$ & 11 & $(7.4)$ & \multirow[t]{2}{*}{0.09} \\
\hline -Urban & 44 & $(84.6)$ & 137 & $(92.6)$ & \\
\hline \multicolumn{6}{|l|}{ Marital status } \\
\hline -Single & 9 & $\begin{array}{l}(17.3) \\
(67.3)\end{array}$ & 35 & $(23.6)$ & \multirow{4}{*}{$0.03^{*}$} \\
\hline -Married & 35 & \multirow{3}{*}{$\begin{array}{l}(67.3) \\
(0.0) \\
(15.4)\end{array}$} & 97 & $(5.4)$ & \\
\hline -Divorced & 0 & & 8 & $(65.5)$ & \\
\hline -Widow & 8 & & 8 & $(5.4)$ & \\
\hline Med in years [Min-Max] & \multicolumn{2}{|c|}{$33[21-70]$} & \multicolumn{2}{|c|}{$28[18-59]$} & \multirow{2}{*}{ - } \\
\hline IQR & \multicolumn{2}{|c|}{$29-41$} & \multicolumn{2}{|c|}{$23-35$} & \\
\hline Med at first sex [Min-Max] & \multicolumn{2}{|c|}{$19[13-17]$} & \multicolumn{2}{|c|}{$19[12-37]$} & \multirow{2}{*}{ - } \\
\hline IQR & \multicolumn{2}{|c|}{$18-21$} & \multicolumn{2}{|c|}{$18-20$} & \\
\hline
\end{tabular}

*Statistically significant result, Med: Median age. 


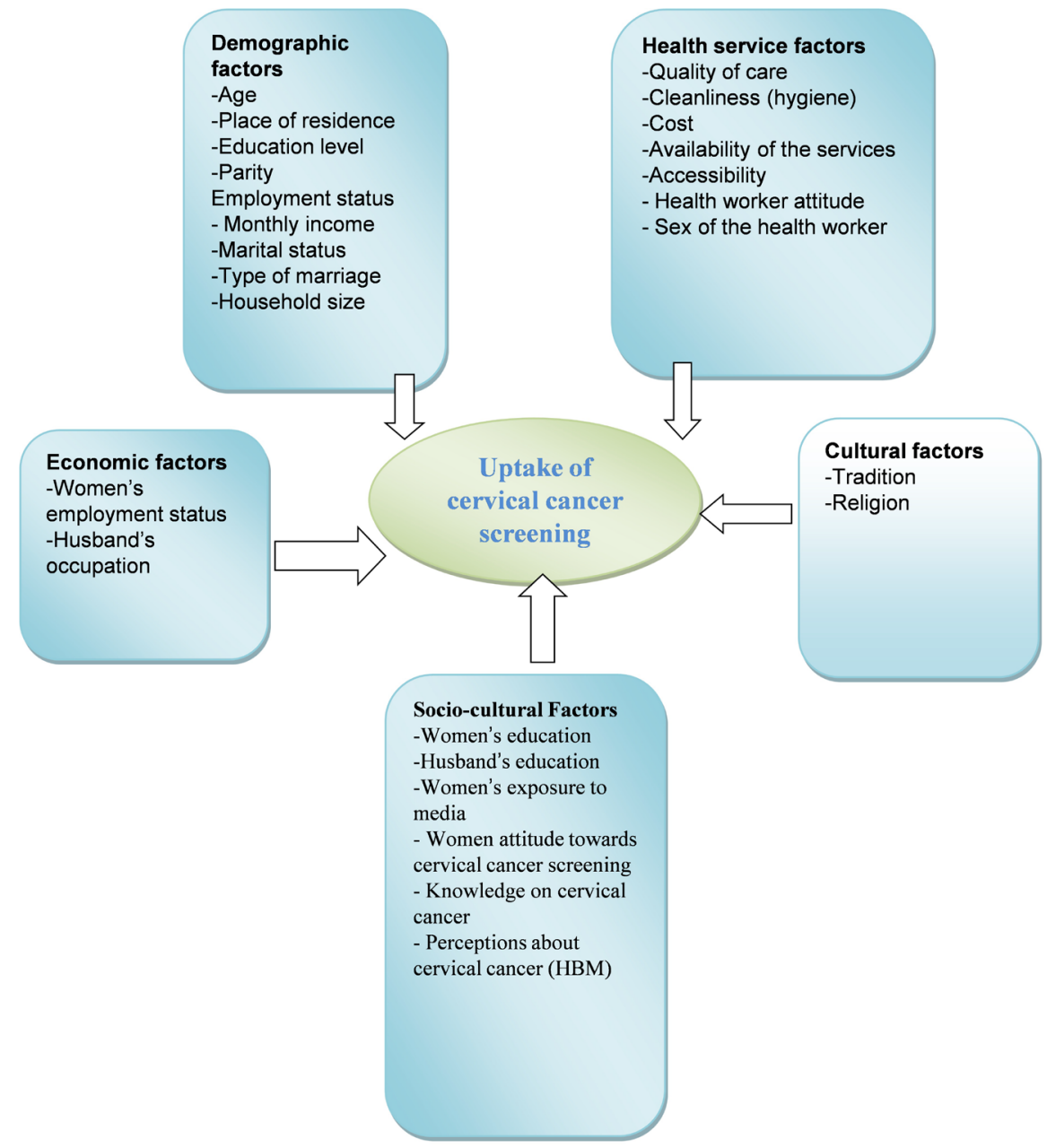

Figure 1. Conceptual framework.

Knowledge of cervical cancer and its screening among women attending health facilities,

Women attending health facilities in Bulawayo were not knowledgeable on the risk factors of cervical cancer. A high proportion of women who had cervical cancer screening reported correctly on the risk factors of cervical cancer (24\%) compared to those who did not have (8\%).

\section{Perceived susceptibility to cervical cancer}

Those who had cervical cancer screening were significantly different from women who did not have the screening with regards to perception of multiple sexual partner ( $\mathrm{P}$-value: 0.0008 ) and 50 years and above as predisposing to cervical cancer (P-value: 0.08 ) (Table 2 ).

\section{Perceived benefits of cervical cancer screening}

The two groups were significantly different in perceiving that screening can find changes in the cervix before they become cancer (p-value: 0.005) and can be cured (p-value: 0.04) (Table 3).

Perceived barriers to seeking cervical cancer screening

The two groups were significantly different in perceiving screening test pain- 
ful as barriers to the uptake of cervical cancer screening. (P-value: 0.00)

Perceived susceptibility to cervical cancer for women who had and did not have cervical cancer screening, Bulawayo, 2012

Those who perceived multiple sexual partners as predisposing to cervical cancer were 4.1 times more likely to go for cervical cancer screening [CI: 1.66 10.37, p-value: 0.001] (Table 2).

Perceived severity of cervical cancer for women who had and did not have cervical cancer screening, Bulawayo, 2012

Women who perceived cervical cancer can cause infertility are twice more likely to go for cervical cancer screening. [CI: 1.03 - 3.95, p-value: 0.04]

Association between Ever heard about screening (awareness) and cervical cancer screening, Bulawayo, 2012

Women who heard about screening were 46.97 times more likely to go for screening than those who never heard about screening [CI: 6.32 - 349.03, p-value: 0.000]

Multivariate analysis of the association between cervical cancer screening and the different perceptions

After controlling for confounders for infertility as perceived severity, fear of positive test as perceived barrier, being woman of child bearing age as perceived susceptibility. Awareness of cervical cancer screening remained a significant factor affecting the uptake of cervical cancer screening [OR: 42.05, CI: 5.63 314.04, p-value: 0.0003] and multiple sexual partners remained significant more perceived as predisposing to cervical cancer among women who had the screening. [OR: 0.33, CI: 0.12 - 0.88, p-value: 0.03] (Table 4).

Table 2. Perceived benefit of cervical cancer screening by participants in Bulawayo city, 2012.

\begin{tabular}{|c|c|c|c|c|c|}
\hline \multirow[t]{2}{*}{ Variable } & \multicolumn{2}{|c|}{$\begin{array}{l}\text { Women who had } \\
\text { |cervical cancer } \\
\text { screening }\end{array}$} & \multicolumn{2}{|c|}{$\begin{array}{l}\text { Women who did not } \\
\text { have cervical cancer } \\
\text { screening }\end{array}$} & \multirow[t]{2}{*}{ p-value } \\
\hline & $\mathrm{N}=52$ & (\%) & $\mathrm{N}=148$ & (\%) & \\
\hline $\begin{array}{l}\text { Cervical cancer screening is } \\
\text { important for your health }\end{array}$ & 52 & (100) & 142 & $(95.9)$ & 0.3 \\
\hline $\begin{array}{l}\text { Cervical cancer screening can } \\
\text { find changes in the cervix before } \\
\text { they become cancer }\end{array}$ & 40 & $(76.9)$ & 92 & $(62.2)$ & $0.005^{*}$ \\
\hline $\begin{array}{l}\text { If detected early cervical cancer } \\
\text { is easily curable }\end{array}$ & 48 & $(92.3)$ & 127 & $(86.4)$ & $0.04^{\star}$ \\
\hline $\begin{array}{l}\text { Screening can help improve the } \\
\text { chances of an infertile woman } \\
\text { becoming pregnant }\end{array}$ & 21 & $(40.2)$ & 62 & $(41.9)$ & $0.0008^{*}$ \\
\hline $\begin{array}{l}\text { Screening can decrease the } \\
\text { chances of a woman having an } \\
\text { abortion }\end{array}$ & 20 & $(38.5)$ & 49 & $(32.2)$ & 0.2 \\
\hline
\end{tabular}

*Statistically significant result. 
Table 3. Perceived susceptibility to cervical cancer for women who had and did not have cervical cancer screening, Bulawayo, 2012.

\begin{tabular}{|c|c|c|c|c|c|c|}
\hline Parameter & & SG & NSG & OR & $95 \% \mathrm{CI}$ & P-value \\
\hline \multirow{2}{*}{$\begin{array}{l}\text { Older women are more at risk } \\
\text { than younger women }\end{array}$} & Yes & 16 & 16 & \multirow{2}{*}{0.63} & \multirow{2}{*}{$0.32-1.24$} & \multirow{2}{*}{0.18} \\
\hline & No & 36 & 87 & & & \\
\hline \multirow{2}{*}{$\begin{array}{l}\text { Every woman of child bearing age } \\
\text { is at risk }\end{array}$} & Yes & 42 & 103 & \multirow{2}{*}{1.83} & \multirow{2}{*}{$0.85-3.98$} & \multirow{2}{*}{0.12} \\
\hline & No & 10 & 43 & & & \\
\hline \multirow{2}{*}{$\begin{array}{c}\text { Women with multiple sexual } \\
\text { partners are more at risk }\end{array}$} & Yes & 46 & 96 & \multirow{2}{*}{4.15} & \multirow{2}{*}{$1.66-10.37$} & \multirow{2}{*}{$0.001^{*}$} \\
\hline & No & 6 & 52 & & & \\
\hline \multirow{2}{*}{$\begin{array}{l}\text { Cervical cancer is more common } \\
\text { to HIV positive women }\end{array}$} & Yes & 23 & 67 & \multirow{2}{*}{0.96} & \multirow{2}{*}{$0.51-1.81$} & \multirow{2}{*}{0.89} \\
\hline & No & 29 & 81 & & & \\
\hline \multirow{2}{*}{$\begin{array}{l}\text { Susceptibility increases with } \\
\text { number of pregnancies }\end{array}$} & Yes & 19 & 49 & \multirow{2}{*}{1.16} & \multirow{2}{*}{$0.60-2.25$} & \multirow{2}{*}{0.65} \\
\hline & No & 33 & 99 & & & \\
\hline \multirow{2}{*}{$\begin{array}{c}\text { Cancer only happens to } 50 \text { Years } \\
\text { and above women }\end{array}$} & Yes & 2 & 16 & \multirow{2}{*}{0.33} & \multirow{2}{*}{$0.07-1.49$} & \multirow{2}{*}{0.13} \\
\hline & No & 50 & 132 & & & \\
\hline
\end{tabular}

*Statistically significant result SG: Screened group, NSG: Not screened group.

Table 4. Perceived susceptibility, benefit, awareness of cervical cancer and screening for women who had and did not have cervical cancer screening in multivariate analysis, Bulawayo, 2012.

\begin{tabular}{cccc}
\hline Parameter & \multicolumn{2}{c}{ Screened group Vs not screened group } \\
\hline $\begin{array}{c}\text { Screening can find } \\
\text { changes in the cervix } \\
\text { before they become cancer }\end{array}$ & 0.60 & $95 \%$ CI & P-value \\
$\begin{array}{c}\text { Multiple sexual partners } \\
\text { Awareness of cervical } \\
\text { cancer screening } \\
\text { (Yes/No) }\end{array}$ & 0.33 & $0.27-1.36$ & 0.22 \\
$\begin{array}{c}\text { Place of } \\
\text { residence } \\
\text { (Urban/Rural) }\end{array}$ & 42.05 & $0.12-0.88$ & \\
\hline
\end{tabular}

\section{Findings from key informants.}

24 health workers involved in the screening programme were interviewed. 91.6\% (22) recognised cervical cancer as a preventable disease, 95.8\% (23) knew about 2 screening methods of cervical cancer Pap smear and VIAC. 91.7\% (22) knew that women of child bearing age are eligible for cervical cancer screening. 91.3\% (21) were screened. Cervical cancer screening was offered in central hospitals only which are Mpilo Hospital and United Bulawayo Hospitals.

16 (68.1\%) Health workers identified poor awareness of cervical cancer, lack of screening centres $13.6 \%$ (3), cost of test $9.1 \%$ (2) and religious beliefs $4.5 \%$ (1) as barriers to cervical cancer screening. 


\section{Discussion}

Our study has revealed that the awareness of cervical cancer screening affect the seeking of cervical cancer screening in Bulawayo. The effect of screening awareness was observed regardless of the place of residence of women attending health facilities in Bulawayo even though the proportion of women living in rural areas was low (10\%).

There were a significantly low proportion of women who had cervical cancer screening among women who attended health facilities and high among health workers. This could be due to awareness because health workers work in the hospital or clinic where the screening is done, they are bound to hear about it and go for it any time they desire and there is a possibility of special care between colleagues. They can be seen before or after hours. This also points to one of the major challenges of cervical cancer screening provision in Zimbabwe, where this service is largely health worker provided and depends on women attending health facilities.

Several studies found a statistically significant improvement in screening uptake in the groups of women who were sent invitation letters compared with those who were not [14].

A study done in Manchester on the attitudes of non-responders found the uptake of cervical cancer screening to be very low (14\%) in spite of the family practitioner committee introducing a call and recall system [15].

Contrary findings were reported in Uganda where the medical workers who should be responsible for opportunistic screening of women they care for are not keen on getting screened themselves [16].

This study has revealed multiple sexual partners as a significant perceived predisposition to cervical cancer in Bulawayo. Cervical cancer is caused by an infection with a general and common HPV, these virus are transmitted through "skin to skin" contact and the cervix mainly through sexual intercourse. Obviously an HPV infection is more common in women varying sex partners, because the probability of encountering an infected partner increases with number of partners. On the other hand, having fewer sexual partners' means you simply have fewer chances to get busy with a person that has an HPV. This is why having multiple sex partners is one of the risk factors for not just HPV, but other STIs including HIV.

This study has shown that cervical cancer screening is perceived as effective in detecting changes in the cervix before they become cancer and can be cured to reduce incidence and mortality of cervical cancer. Similar findings were reported in the Nordic countries, nearly complete coverage of the target population by organised cervical screening programmes in Iceland, Finland, Sweden, and Denmark were soon followed by sharp falls in both incidence and mortality [17].

The majority of women who attended health facilities reported cervical cancer as a preventable disease but with a limited knowledge on the risk factors. This can lead to lack of prevention measures against cervical cancer. Women who had cervical cancer screening were knowledgeable on screening methods because of 
exposure.

Similar findings were reported in Uganda where the authors noted that knowledge about risks for cervical cancer was low among finalists in nursing and medical schools (40\%), but 93\% considered it a Public health problem [18].

Margot A. J. B. Tacken et al. in the Netherlands Showed women's beliefs about cervical screening and attendance are the best predictors of screening uptake, even when demographic and organizational aspects are taken into account [19].

Those perceptions are modified or confounded by place of residence. People living in urban area are exposed to magazines, newspapers, radio, television, and internet; can learn more about anything even cervical cancer and its screening methods.

This study revealed poor awareness of cervical cancer, cost of the screening test, painful screening test, lack of screening centres and religious beliefs are perceived as barriers to the uptake of cervical cancer screening .

Contrary to the findings in United Kingdom, where reasons for non-participation in cervical cancer screening programme were found to be administrative failures, unavailability of a female screener, inconvenient clinic times, lack of awareness of the test's indications and benefits, considering oneself not to be at risk of developing cervical cancer, and fear of embarrassment, pain, or the detection of cancer [20].

\section{Conclusions}

The proportion of women who had cervical cancer screening among women attending health facility was low 52 (26\%).

Awareness of cervical cancer screening was a significant independent factor affecting the uptake of cervical cancer screening and multiple sexual partners perceived as predisposing to cervical cancer was independently associated to the uptake of cervical cancer screening.

Multiple sexual partner and women of 50 years old and above were the most perceived as predisposing to cancer.

The perceived benefits of screening were that screening is important, can find the changes in the cervix before they become cancer and leads to adequate care.

According to Key informant, the barrier to the uptake is lack of awareness and lack of services in the Bulawayo.

We recommended that the Ministry of Health and Child Care Reproductive Health Department and Bulawayo City Council Health department to train all health workers on cervical cancer screening and to ensure the screening is easily available and accessible by having more facilities offering the services.

Bulawayo City Council to conduct awareness campaigns on cervical cancer and its screening methods.

\section{Conflicts of Interest}

The authors declare no conflicts of interest regarding the publication of this paper. 


\section{References}

[1] National Cervical Cancer Coalition. Cervical Cancer Overview. http://www.nccc-online.org/hpvcervical-cancer/cervical-cancer-overview/

[2] MedicineNet.com. Cervical Cancer (Cancer of the Cervix). https://www.medicinenet.com/cervical_cancer/article.htm\#cervical_cancer_facts

[3] PubMEd Healtth. Cervical Cancer Overview. https://www.ncbi.nlm.nih.gov/pubmedhealth/PMH0072443/

[4] U.S. National Library of Medecine. MedlinePlus. https://medlineplus.gov/encyclopedia.html

[5] Centers for Disease Control and Prevention (2000) Breast and Cervical Cancer Prevention and Treatment Act. ftp://ftp.cdc.gov/pub/Publications/Cancer/nbccedp/pdf/publ354-106.pdf

[6] Hamaka, M., Chamberlain, J., Day, N.E., et al. (1985) Evaluation of Screening Programmes for Gynaecological Cancer. British Journal of Cancer, 52, 669-673. https://doi.org/10.1038/bjc.1985.241

[7] World Health Organization (1986) Control of Cancer of the Uterine Cervix. WHO, Geneva.

[8] Hakama, M., et al. (1986) Cervical Cancer: Risk Group for Screening. International Agency for Research on Cancer, 76, 213-219.

[9] Miller, A.B., Chamberlain, J., Day, N.E., et al. (1990) Report on a Workshop UICC Project on Evaluation of Screening for Cancer. International Journal of Cancer, 46, 761-769. https://doi.org/10.1002/ijc.2910460502

[10] Darrell, W. (2011) 2012 Goal: Help Prevent Cervical Cancer in Zimbabwe. Better Healthcare for Africa, Inc.

[11] Zimbabwe National Cancer Registry (2010) Human Papillomavirus and Related Cancers. Summary Report Update.

[12] Zimbabwe National Cancer Registry (2012) Cervical Cancer: Zimbabwe's Silent Epidemic.

[13] Siddiqui, T.R., Ghazal, S., Bibi, S., et al. (2016) Use of the Health Belief Model for the Assessment of Public Knowledge and Household Preventive Practices in Karachi, Pakistan, a Dengue-Endemic City. PLoS Neglected Tropical Diseases, 10, No. 11. https://doi.org/10.1371/journal.pntd.0005129

[14] Everett, T., Bryant, A., Griffin, M.F., et al. (2011) Interventions Targeted at Women to Encourage the Uptake of Cervical Screening. Cochrane Database of Systematic Reviews, 3, CD002834.

[15] Nathoo, V. (1988) Investigation of Non-Responders at a Cervical Cancer Screening Clinic in Manchester. British Medical Journal, 296, 1041-1042.

[16] Sankaranarayanan, R., Nene, B.M., Shastri, S.S., Jayant, K., Muwonge, R., Budukh, A.M., Hingmire, S., Malvi, S.G., Thorat, R. and Kothari, A. (2009) HPV Screening for Cervical Cancer in Rural India. New England Journal of Medicine, 14, 1385-1394.

[17] Global Health Magazine. Courtesy of Jhpiego. http://www.globalhealthmagazine.com/

[18] World Health Organization Regional Office of Africa (2010) Report of an African Regional Meeting on Cervical Cancer. Improve Cervical Cancer Prevention: Planning Now for a Better Future.

[19] Bessler, P., Aung, M. and Jolly, P. (2017) Factors Affecting Uptake of Cervical Cancer Screening among Clinic Attendees in Trelawny, Jamaica. Sage Journals, 14, 
396-404.

[20] Tacken, M.A., Braspenning, J.C., Hermens, R.P., Spreeuwenberg, P.M., van den Hoogen, H.J., de Bakker, D.H. and Groenewegen, P.P. (2007) Uptake of Cervical Cancer Screening in The Netherlands Is Mainly Influenced by Women's Beliefs about the Screening and by the Inviting Organization. European Journal of Public Health, 17, 178-185. https://doi.org/10.1093/eurpub/ckl082 